\title{
ДИСТАНЦИОННЫЙ ПЕРЕХВАТ в волоконно-оптических
} сетях

\author{
В.Гришачев, к.ф.-м.н, доцент кафедры комплексной \\ защиты информации Института информационных наук \\ и технологий безопасности РГГу / grishachev@mail.ru
}

УДК 004.056, DOI: 10.22184/2070-8963.2020.89.4.44.49

Проведенный в статье качественный анализ нелинейно-оптических процессов с информационным сигналом в оптических волокнах (ОВ) показывает возможность генерации информативных паразитных электромагнитных излучений, которые могут быть использованы для дистанционного - без разрушения защитных покровов оптического кабеля (ОК) - перехвата трафика в волоконно-оптических линиях связи (ВОЛС). Эффективность перехвата определяется конструкцией приемной антенны, близостью размещения антенны к оптоволокну, внешним воздействием на ОВ для увеличения его нелинейной восприимчивости. Выявленные особенности технологии перехвата позволили сформулировать требования к средствам технической защиты трафика в ВОЛС, таким как использование шумового сигнала и др.

\section{УГРОЗЫ БЕЗОПАСНОСТИ ПЕРЕДАЧИ} ИНФОРМАЦИИ В ОПТИЧЕСКИХ СЕТЯХ СВЯЗИ Фотонные технологии существенно повышают все характеристики систем передачи информации [1, 2], в частности, скорость, надежность, защищенность. Модель угроз безопасности передачи информации в оптических сетях включает несанкционированный доступ (НСД) и несанкционированный съем информации (НСИ), или перехват. Различие между ними состоит в использовании штатных технических средств волоконно-оптической сети при НСд и средств (нештатных) технической разведки при НСИ (перехвате). Обычно при составлении модели угроз основное внимание уделяется НСД, то есть компьютерной (цифровой) безопасности, а перехват рассматривается исключительно для электрических сетей. Переход от электрических к оптическим сетям создает новые угрозы, которые мало обсуждаются на физическом и техническом уровнях.

Перехват трафика в волоконно-оптических сетях можно определить как несанкционированный съем информации в ВОЛС с помощью средств технической разведки (ТР) путем регистрации информативных сигналов, сопровождающих информационный сигнал в оптическом канале связи [3-9]. Основным способом формирования информативного сигнала является отвод части информационного оптического излучения из канала связи в канал утечки при прямом контакте с OK и волокном путем волоконно-оптической вставки в разрыв канала связи (интрузивный способ [3]) или воздействием на канал без разрыва (неинтрузивный способ [3]). Наиболее опасен последний способ, не требующий легко обнаруживаемого разрыва волокна и использующий энергию информационного сигнала.

Перехват трафика в волоконно-оптических сетях на отводе части информационного оптического сигнала из канала связи в канал утечки без разрыва оптического канала (рис.1) может быть осуществлен на основе:

- вытекающих оптических мод [3], возникающих при вводе оптического излучения 


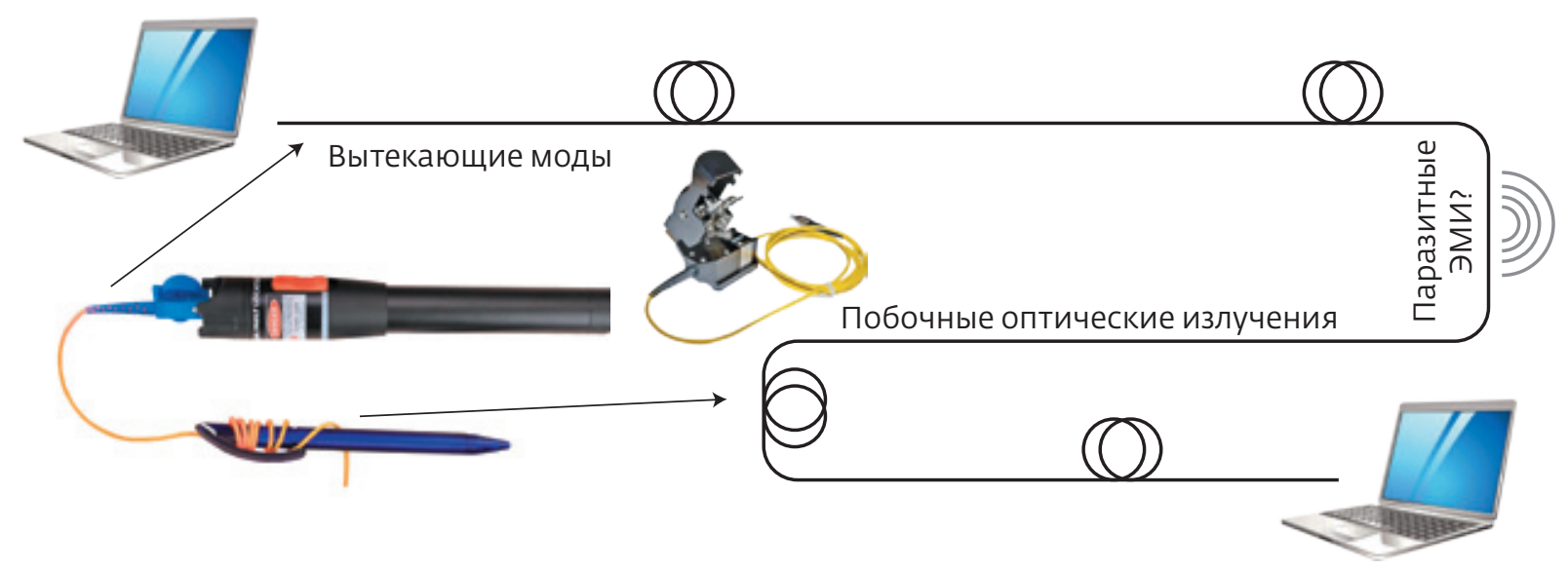

Рис.1. Обобщенная модель перехвата в волоконно-оптических сетях без разрыва волокна

в ОВ кабеля с несогласованными апертурами передатчика и волокна и проявляющееся в виде свечения ОВ при использовании видимых источников света;

- побочных оптических излучений [3-9], связанных с нарушением полного внутреннего отражения при воздействии на волокно физических полей, например, при макроизгибе ОВ в ответвителе-прищепке FOD-5503.

Как правило, при построении модели угроз безопасности информации принимается отсутствие побочных электромагнитных излучений и наводок (ПЭМИН) в оптическом канале связи, что считается главным преимуществом волоконно-оптических систем передачи информации перед электрическими (проводными). По своей природе в линейном приближении распространение оптического излучения не должно сопровождаться электромагнитными излучениями радиодиапазона и более высоких диапазонов частот, но это не исключает появления таких излучений от ОК из-за нелинейно-оптических эффектов [10, 11], которые назовем паразитными электромагнитными излучениями (ПрЭМИ).

Существование ПрЭМИ связывается с модуляцией оптической несущей в информационном сигнале на частотах диапазона СВЧ. Так, в сетях связи с информационной емкостью 10 Гбайт/с частота модуляции несущей имеет порядок 10 ГГц, что соответствует СВЧ-диапазону электромагнитных волн. Демодуляция информационного сигнала в оптическом канале связи вследствие нелинейно-оптических преобразований может привести к генерации информативных электромагнитных излучений, которые могут распространяться от ОK, не имеющего экранирования защитными оболочками.

Таким образом, в волоконно-оптических сетях возможен не только контактный, но и дистанционный перехват, то есть несанкционированный съем информации в линии связи с помощью средств технической разведки путем регистрации информативных радио- и СВЧ-сигналов. В данной работе представлена оценка уровня мощности информативного сигнала в виде ПрЭМИ, анализ возможных типов антенн для регистрации и методы противодействия перехвату.

\section{ИНФОРМАТИВНЫЕ ПАРАЗИТНЫЕ ЭЛЕКТРОМАГНИТНЫЕ ИЗЛУЧЕНИЯ}

Нелинейно-оптические явления в оптическом волокне проявляются в виде [12-14]: 1 - неупругого комбинационного рассеяния (на колебаниях атомов решетки), рассеяния Мандельштама Бриллюэна (на акустических фононах), которые приводят к появлению характерных максимумов и уширению спектра оптического излучения; 2 фазовой самомодуляции, четырехволнового смещения, модуляционной нестабильности, формированию солитонов, фазовой кросс-модуляции, которые оказывают существенное влияние на передачу информации в волоконно-оптических линиях. Данные эффекты связаны с повышением мощности оптического сигнала для увеличения дальности передачи, мультиплексированием большого числа несущих для увеличения информационной емкости канала при уменьшении поперечных размеров волокна. Технология изготовления 


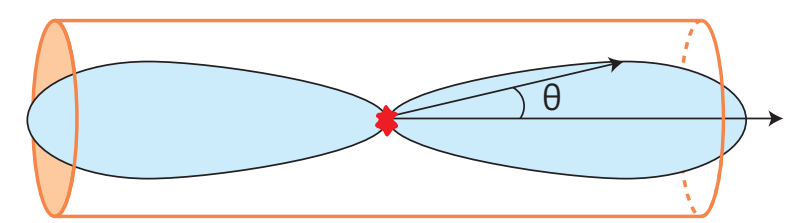

Рис.2. Индикатриса рэлеевского рассеяния на оптических неоднородностях

волокна, представляющая собой процесс вытягивания из преформы (заготовки), вызывает механические напряжения и приводит к появлению дополнительных нелинейностей, которые и проявляются в нелинейно-оптических преобразованиях информационного сигнала.

Нелинейно-оптическое преобразование вызы вает генерацию излучения на комбинационных частотах, в том числе на частоте второй гармоники и разностных частотах. Общая нелинейная поляризация второго порядка материала волокна на частоте $\omega_{3}$ по величине равна

$$
\mathrm{P}_{\mathrm{NL}}=\varepsilon_{0} \mathrm{X}_{\mathrm{NL}} \mathrm{E}_{1} \mathrm{E}_{2}
$$

где $\mathrm{E}_{1}$ и $\mathrm{E}_{2}$ - напряженности электрических полей взаимодействующих волн на частотах $\omega_{1}$ и $\omega_{2}$;

$\mathrm{X}_{\mathrm{NL}}$ - нелинейная восприимчивость второго порядка;

$\varepsilon_{0}$ - электрическая постоянная.

Переходя от нелинейной поляризации к подсчету числа фотонов, выражение примет вид

$$
\mathrm{N}_{3}=\tau \mathrm{N}_{1} \mathrm{~N}_{2} \text {, }
$$

где N1 и N2 - число взаимодействующих фотонов, N3 - число генерируемых фотонов, $\tau$ - коэффициент преобразования, имеющий физический смысл времени эффективного преобразования фотонов, определяемый как

$$
\tau=2 \frac{\mathrm{n}_{1} \mathrm{n}_{2}}{\mathrm{n}_{3}} \frac{\mathrm{h}}{\varepsilon_{0} \mathrm{c} \sigma} \frac{\omega_{1} \omega_{2}}{\omega_{3}} \chi_{\mathrm{NL}}^{2},
$$

где $\mathrm{n}_{1}, \mathrm{n}_{2}, \mathrm{n}_{3}$ - показатели преломления среды на частотах $\omega_{1}, \omega_{2}, \omega_{3}$; $\sigma$ - площадь сечения потока (сердцевины волокна);

с - скорость света в вакууме;

ћ - постоянная Планка.

Представление нелинейной поляризации среды для двухфотонного взаимодействия в виде зависимости числа генерируемых фотонов $\mathrm{N}_{3}$ от числа взаимодействующих $\mathrm{N}_{1}$ и $\mathrm{N}_{2}$ позволяет упростить анализ нелинейных процессов. При взаимодействии соотношение потоков фотонов (интенсивностей) можно считать как $\mathrm{N}_{1} \geq \mathrm{N}_{2} \geq \mathrm{N}_{3}$. Поток генерируемых фотонов $\mathrm{N}_{3}$ имеет наименьшее значение в сравнении со взаимодействующими потоками $\mathrm{N}_{1}$, $\mathrm{N}_{2}$ и не может превышать наименьший поток из взаимодействующих фотонов. Максимум преобразования достигается при $\mathrm{N}_{3}=\mathrm{N}_{2}$, когда за время $\tau=1 / \mathrm{N}_{1}$ все возможные генерации фотонов произойдут. Чем больше один из взаимодействующих потоков, тем эффективнее генерация комбинационных частот и тем более короткое время потребуется для полного преобразования меньшего потока.

Спектр информационного сигнала мощностью $\mathrm{P}_{0}$ на частоте $\omega$ и глубиной гармонической модуляции т на частоте $\Omega$ включает составляющие на частотах $\omega, \omega \pm \Omega$ с направлением распространения от источника (прямой поток) и обратный поток рассеянного излучения Рэлея, отраженного излучения Френеля. В структуре информационного сигнала рассеяние Рэлея (рис.2) определяет потери, являясь когерентным с падающим излучением и практически однородным вдоль ОВ. Индикатриса рассеяния имеет симметричный вытянутый вдоль распространения вид с углом рассеяния $\theta$, часть которого канализируется волокном, а часть покидает его.

Информационный сигнал (см. рис.3) состоит из немодулированных фотонов с энергией ћ山 числом в потоке

$$
\mathrm{N}_{\mathrm{b}}=\mathrm{P}_{0} / \hbar \omega
$$

и модулированных фотонов с энергиями $ћ(\omega-\Omega)$ и $\hbar(\omega+\Omega)$ числом в потоке для каждого типа

$$
\mathrm{N}_{\mathrm{m}}=\mathrm{m}^{2} \mathrm{~N}_{\mathrm{b}} / 2
$$

Кроме фотонов прямого потока в оптоволокне присутствует обратнорассеянные фотоны с энергиями $\hbar \omega, \hbar(\omega-\Omega)$ и $\hbar(\omega+\Omega)$, число которых на участке когерентности порядка пространственной 


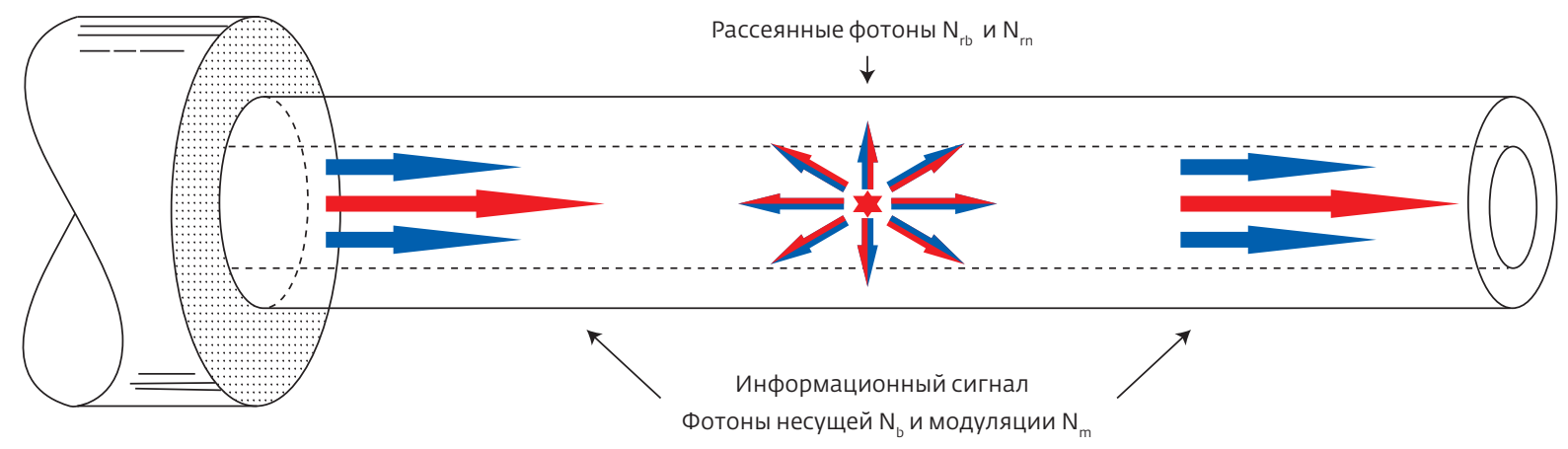

Рис.3. Состав информационного оптического сигнала по частотам и направлениям распространения в волокне

длины бита в полдлины волны модулирующего сигнала $\Lambda=2 \pi \mathrm{c} / \Omega$ на частоте несущей $\omega$ равно

$$
\mathrm{N}_{\mathrm{rb}}=\alpha \Lambda \mathrm{N}_{\mathrm{b}} / 4 \text {, }
$$

а число модулированных фотонов каждой частоты $\omega+\Omega$ равно

$$
\mathrm{N}_{\mathrm{rm}}=\mathrm{m}^{2} \alpha \Lambda \mathrm{N}_{\mathrm{b}} / 8
$$

где дополнительное уменьшение в два раза связано с симметричностью индикатрисы рассеяния.

Демодуляция информационного оптического сигнала в информативный паразитный электромагнитный сигнал происходит при нелинейном взаимодействии основной и модулированной волн с генерацией сигнала разностной частоты. В информационном потоке условием эффективной генерации разностных частот является выполнение законов сохранения энергии

$$
\hbar \omega_{1}+\hbar \omega_{2}=\hbar \omega_{3}
$$

и импульса

$$
\hbar \vec{k}_{1}+\hbar \vec{k}_{2}=\hbar \vec{k}_{3}
$$

Здесь $\vec{k}_{1}, \vec{k}_{2}, \vec{k}_{3}$ - волновые векторы взаимодействующих и генерируемых излучений (рис.4).

При антиколлинеарном и неколлинеарном взаимодействии в приближении близости частот $\omega_{1}$, $\omega_{2} " \omega_{3}$, так как можно принять $\mathrm{n}_{1} \approx \mathrm{n}_{2}=\mathrm{n}$ - показателю преломления сердцевины волокна на частотах $\omega_{1}$ и $\omega_{2}, \mathrm{n}_{3} \approx 1$ на частоте $\omega_{3}$ и малости угла рассеяния $\theta$, получаем

$$
\omega_{3}=n\left(\omega_{2}-\omega_{1}\right) .
$$

Разностная частота генерируемого излучения определяется типами фотонов, принимающих участие во взаимодействии, она может принимать значения

$$
\omega_{3}=\mathrm{n} \Omega ; 2 \mathrm{n} \Omega,
$$

где первая частота генерируется при взаимодействии фотонов частотой несущей $\omega_{1}=\omega$ и одной из модулированных волн $\omega_{2}=\omega \pm \Omega$, а удвоенная - при взаимодействии модулированных волн $\omega_{1}=\omega-\Omega$ и $\omega_{2}=\omega+\Omega$ с противоположным направлением волновых векторов.
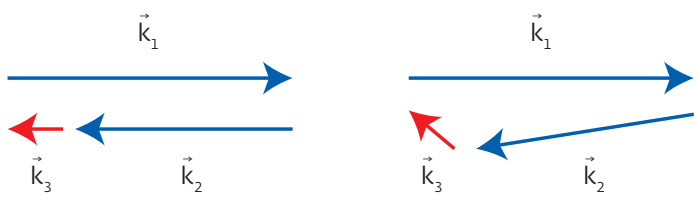

Рис.4. Условие фазового синхронизма в средах с квадратичной нелинейностью для волновых векторов при антиколлинеарном и неколлинеарном направлениях взаимодействующих и генерируемых излучений: $\vec{k}_{1}+\vec{k}_{2}=\vec{k}_{3}$ 
Демодуляция приводит к генерации излучения на частоте $\omega_{3}$, которая относится к радиодиапазону, и для него диэлектрическое оптоволокно не является волноводом. Это излучение распространяется во все стороны от кабеля, формируя информативный паразитный электромагнитный сигнал.

Оценим мощность излучения на частоте $\omega_{3}=\mathrm{n} \Omega$ по числу генерируемых фотонов на данной частоте, которые включают процессы взаимодействия:

- несущей в прямом направлении ( $\mathrm{N}_{\mathrm{b}}$ фотонов) и обратнорассеянной модулированной волны ( $2 \mathrm{~N}_{\mathrm{rm}}$ фотонов);

- обратнорассеянной несущей ( $\mathrm{N}_{\mathrm{rb}}$ фотонов) и модулированной волны в прямом направлении ( $2 \mathrm{~N}_{\mathrm{m}}$ фотонов).

Определяемое по меньшему числу участвующих во взаимодействии фотонов общее максимально возможное число фотонов демодуляции на частоте $\mathrm{nf}$ равно

$$
\mathrm{N}_{\mathrm{rb}}+2 \mathrm{~N}_{\mathrm{rm}}=\alpha \Lambda \mathrm{N}_{\mathrm{b}}\left(1+\mathrm{m}^{2}\right) / 4,
$$

что соответствует максимуму мощности информативного паразитного электромагнитного сигнала

$$
\mathrm{P}_{\mathrm{i}}=\frac{\alpha \lambda}{4}\left(1+\mathrm{m}^{2}\right) \mathrm{P}_{0} \text {. }
$$

\section{ОЦЕНКА УРОВНЯ УГРОЗ ДИСТАНЦИОННОГО ПЕРЕХВАТА}

Нелинейно-оптические процессы в волокне являются основой демодуляции оптической несущей и формирования информативного паразитного электромагнитного излучения путем генерации сигналов разностной частоты. Для проведения оценок в качестве модели информационного сигнала используем простейшую гармоническую модуляцию на частоте $\mathrm{f}=1$ ГГц $(\Omega=2 \pi \mathrm{f})$ по амплитуде с коэффициентом модуляции $\mathrm{m} \leq 1$ монохроматической оптической несущей на длине волны $\lambda=1550$ нм (частотой $v=1,9 \cdot 10^{14} \Gamma ц, \omega=2 \pi v$ ) мощностью $\mathrm{P}_{0}=1$ мВт. В качестве модели среды волоконно-оптического канала примем одномодовое волокно из аморфного кварца $\left(\mathrm{SiO}_{2}\right)$ с диаметром сердцевины $\mathrm{d}=10$ мкм, показателями преломления сердцевины/оболочки $\mathrm{n}=1,46 / 1,45$, коэффициентом поглощения $\mathrm{a}=5,1 \cdot 10^{-5} \mathrm{M}^{-1}(0,22$ дБ/км $)$ и характерной нелинейностью второго порядка для аморфного кварца $\mathrm{x}_{\mathrm{NL}}=10^{-11} \div 10^{-13} \mathrm{M} / \mathrm{B}$.

В принятом приближении максимальная мощность паразитных электромагнитных излучений от участка длиной $\Lambda / 2=0,1$ м на частоте $\mathrm{n} \cdot \mathrm{f}=1,45$ ГГц при 100\%-ной глубине модуляции $\mathrm{m}$ и квадратичной нелинейности $\mathrm{x}_{\mathrm{NL}} \approx 10^{-8} \mathrm{M} / \mathrm{B}$ имеет значение порядка $\mathrm{P}_{\mathrm{i}}=4 \cdot 10^{-14}$ Вт. В реальном волокне квадратичная нелинейность на три порядка меньше, что позволяет оценить мощность паразитных электромагнитных излучений от участка волокна длиной 10 см на частоте 1,45 ГГц в $10^{-19}$ Вт. Переход к модуляционным частотам 10 ГГц приводит к генерации ПрэМИ с мощностью $10^{-19}$ Вт от участка волокна длиной $1 \mathrm{~cm}$ на частоте 14,5 ГГц.

При всей малости ПрЭМИ можно значительно повысить эффективность регистрации информативного сигнала путем интегрирования когерентных между собой сигналов от нескольких участков волокна многоэлементной антенной (рис.5). Например, при передаче 10 Гбит/с на участке волокна в 1 м можно расположить 100 антенн длиной 1 см каждая и увеличить мощность информативного сигнала на четыре порядка. Еще один способ увеличить мощность информативного ПрЭМИ состоит в использовании для перехвата участков волокна с оптическими неоднородностями, таких как точка сварки, где локальное рассеяние много больше и выше квадратичная нелинейность. В этом случае можно обойтись одноэлементной антенной.

Дополнительное увеличение мощности информативного ПрэМИ может быть осущест влено путем воздействия физических полей на волокно для повышения нелинейно-оптической восприимчивости, например путем механического давления, скручивания, воздействия электрических и магнитных полей и других видов.

\section{МЕТОДЫ ПРОТИВОДЕЙСТВИЯ}

Физический анализ процессов формирования информативных сигналов позволяет предложить такие методы противодействия перехвату:

- использование высококачественного оптоволокна и соответствующих всем установленным требованиям методов монтажа волоконно-оптической сети, что позволит уменьшить мощность ПрЭМИ;

- высокоточный мониторинг качества состояния волоконно-оптической сети, что позволит выявить участки ОВ с повышенной нелинейно-оптической восприимчивостью;

- подача в оболочку ОВ когерентного шумового сигнала на частотах, отличных от информационного, но с шириной полосы, близкой к ширине полосы информационного сигнала, что приведет к зашумлению информативного сигнала; 


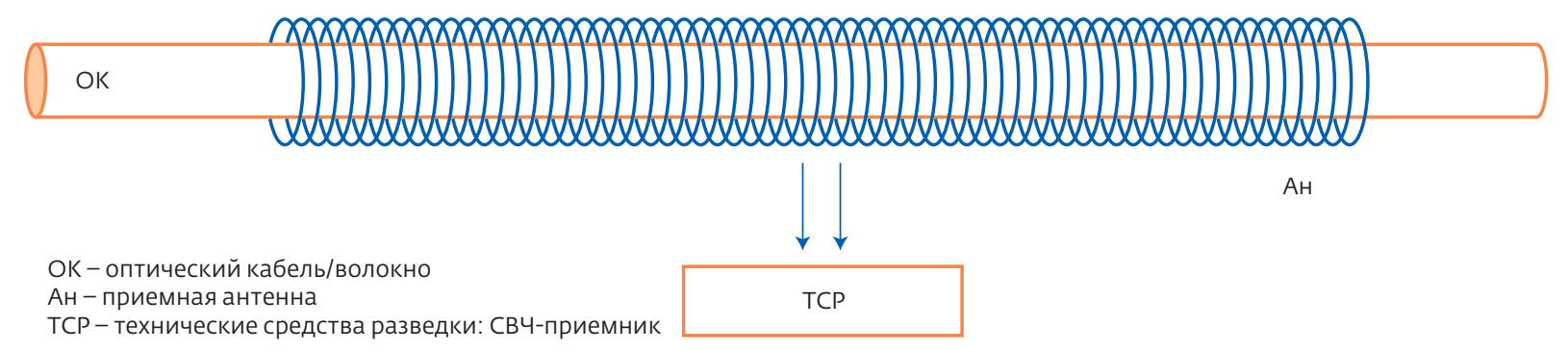

Рис.5. Возможные виды антенн

- мультиплексирование информационного и шумового сигналов непосредственно в сердцевине волокна с полосой, близкой к ширине полосы самого информационного сигнала.

Однако говорить о наличии радикального способа защиты будет можно только после проведения дополнительных теоретических, а главное, экспериментальных и практических исследований данного канала утечки информации.

\section{ЛИТЕРАТУРА}

1. Волоконно-оптическая техника: Современное состояние и перспективы // Сб. ст. / Под ред. С.А.Дмитриева и Н.Н.Слепова. - М.: ООО "Волоконно-оптическая техника", 2005. $576 \mathrm{c}$.

2. Скляров О.К. Волоконно-оптические сети и системы связи. - СПб: Изд-во "Лань", 2010. $272 \mathrm{c}$.

3. Шубин В.В. Информационная безопасность волоконно-оптических систем. - Саров: РФЯЦ-ВНИИЭФ, 2015. 257 с.

4. Корольков А.В., Кращенко И.А., Матюхин В.Г., Синев С.Г. Проблемы защиты информации, передаваемой по волоконно-оптическим линиям связи, от несанкционированного доступа // Информационное общество. 1997. № 1. С. 74-77.

5. Гришачев В.В., Кабашкин В.Н., Фролов А.Д. Анализ каналов утечки информации в волоконно-оптических линиях связи: нарушение полного внутреннего отражения // Информационное противодействие угрозам терроризма. 2005. № 4. С. 194-204.
6. Боос А.В., Шухардин О.Н. Анализ проблем обеспечения безопасности информации, передаваемой по оптическим каналам связи, и путей их решения // Информационное противодействие угрозам терроризма. 2005. № 5. С. 162-170.

7. Свинцов А.Г. Оптимизация параметров оптического рефлектометра для обнаружения неоднородности при попытке несанкционированного доступа в ВОСП // Фотон-Экспресс. 2006. № 6(54). С. 56-71.

8. Булавкин И.А. Вопросы информационной безопасности сетей PON // Технологии и средства связи. 2006. № 2. С. 104-108.

9. Глущенко А., Глущенко Л., Тупота В. Оценка защищенности информации, циркулирующей в ВОЛП // Фотоника. 2010. Т. 4. № 4. С. 36-42.

10. Гришачев В.В. Анализ каналов утечки информации в волоконно-оптических линиях связи: паразитные электромагнитные излучения // Комплексная защита информации: материалы XXIV науч.-практ. конф. Витебск, ВГТУ, 21-23 мая 2019 г. С. 44-52.

11. Гришачев В.В. Перехвата трафика в оптических сетях: информативные паразитные электромагнитные излучения // Фотоника. 2019. Т. 13. № 3. С. 280-294. https://doi. org/10.22184 / FRos.2019.13.3.280.294.

12. Шен И.Р. Принципы нелинейной оптики. М.: Наука, 1989. 560 с.

13. Агровал Г.П. Нелинейная волоконная оптика / Пер. с англ. - М.: Мир, 1996. 323 с.

14. Дмитриев В.Г., Тарасов Л.В. Прикладная нелинейная оптика. - М.: Физматлит, 2004. 512 с. 


\section{ЭКЗ модернизирует экструзионное оборудование}

На финальную стадию вышла модернизация уже третьей по счету экструзионной линии в цехе № 4 AO "Электрокабель" Кольчугинский завод" (ЭКЗ), входящего в "Холдинг Кабельный Альянс".

Новые экструдеры установлены, идет их отладка. При этом, в связи с пандемией, все обсуждения технических вопросов с наладчиками фирмы-производителя идут онлайн - посредством электронной почты.
С вводом в строй обновленной линии в цехе увеличатся мощности по производству кабелей связи, управления и контрольных кабелей.

"В последние годы произошел номенклатурный сдвиг. Традиционные медные кабели связи, которые завод выпускал многие годы, стали вытесняться более сложными по конструкции кабелями управления и волоконно-оптическими кабелями. Поэтому те мощности, которыми мы располагали, нас попросту уже не удовлетворяют Чтобы соответствовать ожиданиям рынка и успевать за растущим спросом мы приняли решение провести в 2020 году модернизацию всех экструзионных линий в цехе № 4", - пояснил главный технолог АО "ЭКЗ" Анатолий Баринов.

По информации АО "Электрокабель" Копьчугинский завод"

\section{Отечественное телекоммуникационное оптическое волокно включено в реестр российской радиоэлектронной продукции}

22 июня 2020 года Министерство промышленности и торговли России включило оптическое волокно, производимое в Саранске (Республика Мордовия) АО "Оптиковолоконные Системы" (ОВС), в единый реестр российской радиоэлектронной продукции, созданный в соответствии с постановлением Правительства Российской Федерации от 10 июля 2019 года № 878.

Ранее в реестр были включены также оптические кабели большинства крупных отечественных кабельных заводов, изготавливаемые с использованием оптического волокна производства ОВС.

Реестр радиоэлектронной продукции РФ позволяет реализовать ряд дополнительных мер государственной поддержки отечественных производителей оптических кабелей и волокна в рамках политики импортозамещения.

Как отмечается в пресс-релизе ОВС, стимулирование развития производства российского телекоммуникационного оборудования является одной из задач федерального проекта "Информационная инфраструктура" национальногопроекта"ЦЦифровая экономика". Единый реестр радиоэлектронной продукции призван упорядочить процедуры проведения закупок как для российских производителей телекоммуникационного оборудования и кабельной продукции, так и для заказчиков.

По информации

АО "Оптиковопоконные Системы"

\section{КНИГИ ИЗДАТЕЛЬСТВА "ТЕХНОСФЕРА»}

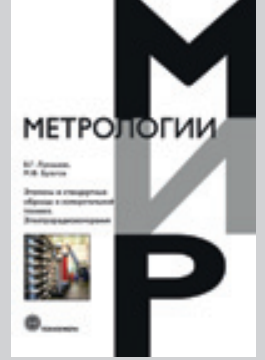

Цена 840 руб.

\section{ЭТАЛОНЫ И СТАНДАРТНЫЕ ОБРАЗЦЫ В ИЗМЕРИТЕЛЬНОЙ ТЕХНИКЕ. ЭЛЕКТРОРАДИОИЗМЕРЕНИЯ}

\author{
Лукашкин В.Г., Булатов М.Ф.
}

Издание осуществиено при финансовой поддержке Федерапьного агентства по печати и массовым коммуникациям в рамках Федерапьной целевой программы "Купьтура России (2012-2018 20ды)"

В книге рассмотрены общие вопросы метрологического обеспечения и единицы физических величин. Изложены основные задачи технических средств метрологического обеспечения в области электрорадиоизмерений. Даны методы воспроизведения единиц физических величин на основе современных научно-технических достижений с использованием квантовых эффектов и фундаментальных физических констант.

Книга может быть полезна студентам и аспирантам при выборе и обосновании эталонной базы в области электрорадиоизмерений, а также специалистам, занимающимся вопросами разработки, производства и оценки качества средств измерений, контроля и испытаний. 


\section{Консорциум ведущих автопроизводителей и телекомкомпаний успешно завершил проект ConVeX C-V2X}

Audi, Ericsson, Qualcomm Technologies, SWARCO Traffic Systems и Технический университет Кайзерслаутерна сообщили об успешном завершении первых объявленных в мире испытаний технологии обмена информацией между транспортным средством и его окружением - C-V2X. Начавшиеся в декабре 2016 года испытания включали стендовые и полевые тесты на основе спецификаций C-V2X Партнерства ЗGPP для прямого и сетевого взаимодействия подключенных автомобилей и интеллектуальных транспортных систем (Intelligent Transportation Systems, ITS). Целью испытаний было дальнейшее подтверждение взаимодополняющей природы сотовой и близкой прямой связи в технологии C-V2X. Полученные результаты продемонстрировали надежность и эффективность коммуникаций V2X (vehicle-to-everything).

В 2016 году партнеры сформировали консорциум ConVeX (Connected Vehicle-to-Everything of Tomorrow) и теперь успешно завершили и проанализировали результаты тестирования сквозной реализации и эффективности технологии в условиях, максимально приближенных к реальным. В ходе выполнения проекта консорциум ConVeX, в финансировании которого принимает участие Федеральное министерство транспорта и цифровой инфраструктуры Германии (BMVI), испытал и продемонстрировал несколько вариантов применения технологии C-V2X, включая прямую связь автомобиля с автомобилем (Vehicle-to-Vehicle, V2V) и автомобиля с инфраструктурой (Vehicleto-Infrastructure, V2I) в диапазоне частот ITS (5,9 ГГц), а также связь автомобиля с территориальной сетью (Vehicle-to-Network, V2N). Для этих испытаний использовались автомобили Audi и элементы интеллектуальной дорожной инфраструктуры SWARCO, оснащенные технологией C-V2X на базе платформы Qualcomm 9150 C-V2X. ConVeX исследовал надежность, дальность и эффективность прямой связи C-V2X в диапазоне 5,9 ГГц между автомобилями и инфраструктурой на разных скоростях.

Тесты показали 100\% надежный прием предупреждающих сообщений в условиях прямой видимости на расстоянии до 1,2 км (дальность ограничивалась длиной испытательных трасс). Тестирование проводилось в Германии на трассах А9 и А6 при относительной скорости двух автомобилей, движущихся в противоположных направлениях, до 430 км/ч. Тесты также проводились в городских условиях на абсолютно "слепых" перекрестках. Они показали, что предупреждающие сообщения V2V доставляются со 100\%-ной надежностью на расстоянии как минимум 140 м. Это подтверждает высокую эффективность прямой связи C-V2X в таких ситуациях, как помощь при проезде перекрестка, при левом повороте и предупреждение о лобовом столкновении.

По информации компании Qualcomm Technologies

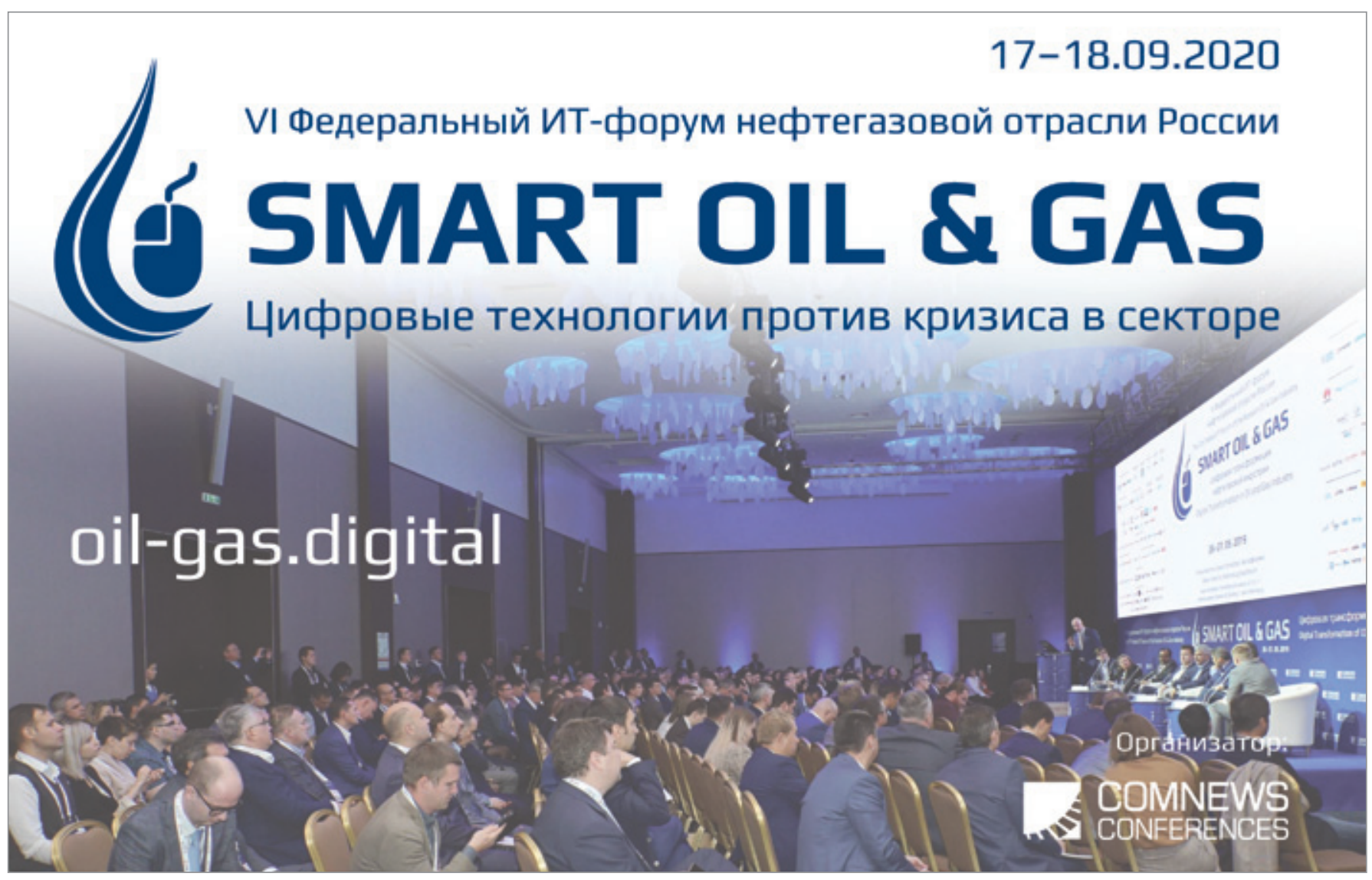

